\title{
Analysis of the Clonal Diversity of Staphylococcus aureus Methicillin-resistant Strains Isolated at João Pessoa, State of Paraíba, Brazil
}

\author{
Lauro Santos Filho ${ }^{+}$, Helio Silva Sader *,Vania I Bortolotto*, Paulo P \\ Gontijo Filho**, Antonio C Pignatari*
}

\author{
Departamento de Ciências Farmacêuticas, UFPb, Cidade Universitária, 58069-900 João Pessoa, PB, Brasil \\ *Disciplina de Doenças Infecciosas e Parasitárias, Escola Paulista de Medicina, São Paulo, SP, Brasil \\ **Instituto de Microbiologia, Universidade Federal do Rio de Janeiro, RJ, Brasil
}

To investigate the clonal diversity of Staphylococcus aureus strains isolated at João Pessoa, State of Paraíba, Brazil, digested genomic DNA were studied by pulsed-field gel electrophoresis (PFGE) in nine methicillin-resistant strains (MRSA) and three methicillin-sensitive strains (MSSA), selected among 67 isolates based on their antimicrobial susceptibility and epidemiology. The isolates were obtained between April and November 1992 from the Hospital of the Federal University of Paraíba, located in João Pessoa. Two MRSA isolates from the Oswaldo Cruz Hospital, São Paulo, Brazil, including an epidemic strain previously detected from different hospitals at the country were used as control. Five different patterns, were demonstrated by MRSA isolated in João Pessoa and these patterns were described in several epidemiologically unrelated hospitals in São Paulo. Our results suggest the interstate dissemination of a MRSA clone in João Pessoa which is similar to that described in other cities of Brazil.

Key words: Staphylococcus aureus - molecular epidemiology - antimicrobial resistance

Methicillin-resistant staphylococci has emerged over the past 30 years as an important cause both nosocomial and community acquired infections (Halley et al. 1982, Boyce et al. 1994). The prevalence of methicillin-resistant Staphylococcus aureus (MRSA) in Brazil is considered elevated, specially in large and/or university hospitals (Branchini et al. 1993, Sader et al. 1994). In addition, the multidrug resistance has become a serious problem to the treatment and implementation of control measures in the hospitals (Boyce et al. 1994). The multiple-drug may provide MRSA strains with a selective advantage for nosocomial colonization and subsequent spread (Struellens et al. 1992).

Resistance to methicillin is usually expressed heterogeneously and the sensitivity of susceptibility tests may be low because several factors can influence the phenotipic expression of resistance (Hackbarth \& Chambers 1989), which is primarily mediated by the production of an altered penicillin-binding protein (PBP 2a). Different from the other constitutive PBPs, this cell wall enzyme has a low affinity for $\beta$ lactams antibiotics and allows

This study was supported in part by CNPq (N0 400.196/ 93-0).

${ }^{+}$Corresponding author

Received 25 January 1995

Accepted 19 October 1995 cell wall formation in concentrations of drugs that render the other PBPs inactive (Hartman \& Tomasz 1984). The PBP 2a and the gene encoding it (mecA) have been found in all resistant staphylococci (De Lencastre et al. 1991), and their detection may be used as reference procedure when other tests provide ambiguous results (Richard et al. 1993). The Crystal MRSA system is a qualitative screening method for the rapid detection of intrinsic methicillin resistance and there was a close correlation between the presence of gene mec and a positive reaction with this test (Knapp et al. 1994).

Traditional and molecular analysis have been extensively used for epidemiologic evaluation of MRSA infections (Struellens et al. 1992, Schilichting et al. 1993). The similarity among epidemiologic unrelated strains make their analysis very difficult. Several studies have recommended the use of a molecular technique, such as pulsed-field gel electrophoresis (PFGE). This methodology is reported to be very sensitive, hightly reproducible and to have a very good discriminatory power (Prevost et al. 1992).

In the present study we report the value of genomic DNA digestion using rare-cutting restriction endonuclease and PFGE as epidemiological tools for monitoring MRSA infections in the Hospital of the Federal University of Paraíba and also follow the genetic development of natural populations. 


\section{MATERIALS AND METHODS}

Bacterial strains - The strains were collected between April and November 1992 in 220 beds at the Hospital of the Federal University of Paraíba, a reference hospital for the surrounding area, located at João Pessoa, state of Paraíba, Brazil. Among 67 isolates of $S$. aureus, with 21 MRSA (31.4\%) and 46 MSSA $(68.6 \%)$, obtained from several clinical cases, we evaluated 12 strains which were sellected due to their multiresistance to antimicrobial agents. All isolates were identified as $S$. aureus by colony morfology, Gram stain, production of catalase, coagulase and DNAse, and sorology test (Kloos \& Lambe 1991). Two MRSA isolates from the Oswaldo Cruz Hospital (São Paulo, SP), including an epidemic strain previously detected at different hospitals in Brazil were used as control (Sader et al. 1994).

Oxacillin resistance - Agar screen tests for oxacillin resistance were performed by the use of Mueller-Hinton Agar supplemented with $4 \% \mathrm{NaCl}$ and $6 \mu \mathrm{g} / \mathrm{ml}$ oxacilin (Thornsberry \& McDougal 1983), and confirmed by the Crystal MRSA ID System (Becton Dickinson, Cooekeysville, MD, USA) (Qadri el al. 1994). The minimum inibitory concentrations (MICs) were determined by E-Test (AB Biodisk, Solna, Sweden) (Brown \& Brown 1991). Oxacillin resistant strains were defined as an oxacillin $\mathrm{MIC} \geq 4 \mu \mathrm{g} / \mathrm{ml}$ in a $2 \% \mathrm{NaCl}$ supplemented, cation adjusted Mueller-Hinton broth.

Susceptibility testing - An extensive multidrug antibiogram using 23 antibiotics was performed on the 12 isolates. The MICs were determined by a standardized broth microdilution method using procedures described by the National Committee for Clinical Laboratory Standards (NCCLS 1993). The drugs were obtained from their manufacturers and included beta lactams (methicillin, oxacillin and penicillin), fluoroquinolones (ciprofloxacin), glycopeptides (LY-264826, MDL-62873, ramoplanin, teicoplanin, vancomycin), macrolides (azithromycin, clarthromycin, clindamycin, erytromycin, roxithromycin), streptogramin (RP59500), aminoglycosides (amikacin, gentamicin and tobramycin) and other antimicrobial agents used to treat staphylococcal infections (cloranphenicol, mupirocin, rifampicin and tetracycline). The isolates were classified as susceptible or resistant to the other antibiotics according to established NCCLS breakpoint values (NCCLS 1993).

Phagetyping - The strains were tested against the International Basic Phage Set and experimental phages, at the University of São Paulo at Ribeirão Preto, Brazil. The strains were tested at $1 \mathrm{x}$ routine test dilution (RTD), when the result was negative, the isolate was retested with 100x RTD (Blair \& Williams 1961).
Molecular analysis by PFGE - It was performed in agarose plugs bands according to Pfaller et al. (1994). The isolates were picked from Columbia Agar supplemented with $5 \%$ blood and grown overnight at $37^{\circ} \mathrm{C}$ in Triptic Soy Broth (TSB/Difco) with agitation, to ensure aeration and high bacterial yield. The bacterial suspension was centrifuged, washed and ressuspended in salina. The suspension was then transferred to tube containing lysis buffer (6mM Tris, $\mathrm{pH} 7,5 ; \mathrm{NaCl} 1 \mathrm{M}$; EDTA 0,1M; Brij 58 0.5\%; Sodium Desoxycholate $0.5 \%$; Sarcosyl $0.5 \%$ ) and $20 \mu \mathrm{l}$ Lysostaphin (Sigma, St. Louis, MO, USA). This solution was mixed with $2 \%$ liquid low melting point agarose (inCERT GTG, FMC Bioproducts, USA). This mixture was poured into slots of a plastic mold (BioRad) and cooled. The agarose plugs obtained were incubated with EC during $5 \mathrm{hr}$, and washed two times with CHEF TE solution (Tris 0,1M, pH 7,5; EDTA 0,1M, pH 7,5). Digestion was performed with ES solution (EDTA 0,4M, pH 9,3; Sarcosyl 1\%) and Proteinase K (1mg/ml), incubated overnight at $50^{\circ} \mathrm{C}$. Lysed bacterial material and proteinase $\mathrm{K}$ activity were eliminated by four washes in CHEF TE. Macrorestriction of genomic DNA was carried out by placing 1/3 of each plug in restriction buffer incubated overnight at room temperature, with 20U of Sma I (New England Biolabs, Beverly, USA) according to the manufacturer's instructions. Plugs containing the restricted DNA were inserted into $1 \%(\mathrm{w} / \mathrm{v})$ agarose gel (Seakern GTG, FMC Bioproducts, USA). Electrophoresis was performed with a CHEF DR II (BioRad Laboratoires, Richmond, CA, USA) at $200 \mathrm{v}(6 \mathrm{v} / \mathrm{cm})$, for $23 \mathrm{hr}$ at $13^{\circ} \mathrm{C}$, in a buffer $5 \times \mathrm{TBE}$ (tris hidrocloride, boric acid, EDTA), with pulse times ranging from 5 to $30 \mathrm{sec}$. A lambda DNA polimer (BioRad) was used as a molecular size marker. The gel was stained with ethidium bromide, rinsed and photographed under UV light.

PFGE patterns were considered identical if they shared every band, similar (subtype) if they differed by only one or two clearly visible bands, and different if they differed by three or more bands.

\section{RESULTS}

The results demonstrate the potential utility of PFGE after digestion with restriction endonuclease enzime protocol in the epidemiological analysis of such strains. The clinical and epidemiological aspects of the studied strains are presented in Table $\mathrm{I}$, including the lysotyping and the PFGE patterns demonstrated by $S$. aureus isolates after digestion with Sma I endonuclease.

All 12 strains were resistant or susceptible to the same drugs, and the MIC did not differ significantly from one strain to another (Table II). All strains were susceptible to all glycopeptides 
tested, and to the new streptogramin RP-59500. Other drugs to which the epidemic strain was susceptible included mupirocin and rifampicin. However, mupirocin is available only for topical use and rifampicin can not be used alone to treat staphylococcal infections.
Five different PFGE profile were demonstrated among 12 MRSA from João Pessoa (Fig.), and the São Paulo pattern was determined in $41.8 \%$ of the strains evaluated. All isolates within a set were compared in a single gel, and the profiles were compared visually.

TABLE I

Clinical and epidemiological aspects of the twelve studied Staphylococcus aureus strains

\begin{tabular}{lllcccc}
\hline Number & \multicolumn{1}{c}{ Ward } & Anatomic site & Phagic group & Phagic type & CHEF & Oxa \\
\hline 01JP02 & Neonatology & Umbilical stump & NT & NT & SP & R \\
02JP05 & Medical Clinic & Cutaneous ulcer & NT & NT & SP & R \\
03JP171 & Surgical Clinic & Surgical wound & V & 94 & SP & R \\
04JP189 & Surgical Clinic & Surgical wound & NT & NT & SP & R \\
05JP190 & Surgical Clinic & Surgical wound & NT & NT & SP & R \\
06JP04 & Surgical Clinic & Abscess & III & 54 & A & R \\
07JP12 & Obstetrics & Surgical wound & NT & NT & B & S \\
08JP14 & Medical Clinic & Decubitus ulcer & III+Extra & 83a, 89, 92 & C & R \\
09JP15 & Surgical Clinic & Surgical wound & III+Extra & $83 \mathrm{a}, 92$ & D & R \\
10JP16 & ITU & Bronchic Sec. & III+Extra & $83 a, 92$ & D & S \\
11JP187 & Infectious Dis. & Decubitus ulcer & NT & NT & E & S \\
12JP197 & Medical Clinic & Decubitus ulcer & III+Extra & $83 \mathrm{a}, 89$ & D & R
\end{tabular}

$\mathrm{CHEF}=$ Contour-clamped homogeneous electrical field; $\mathrm{SP}=\mathrm{São}$ Paulo pattern; $\mathrm{R}=$ resistence; $\mathrm{S}=$ susceptibility (NCCLS 1993)

\section{TABLE II}

Susceptibility and MIC $(\mu \mathrm{g} / \mathrm{ml})$ value or range of the 12 Staphylococcus aureus isolates against 23 antimicrobial agents

\begin{tabular}{llccc}
\hline \multicolumn{1}{c}{ Antimicrobial agent } & \% Susceptibility & MIC/OxaR & MIC/OxaS \\
\hline \multirow{2}{*}{ Penicillins } & Penicillin & 0 & $\geq 2$ & $1-\geq 2$ \\
& Oxacillin & 25 & $\geq 16$ & $\geq 0,25$ \\
Fluoroquinolones & Methicillin & 33 & $\geq 64$ & -4 \\
Glycopeptides & Ciprofloxacin & 67 & $0,25-\geq 8$ & $0,12-\geq 8$ \\
& MDL 62875 & 100 & $\leq 0,12-0,25$ & $\leq 12$ \\
& LY 264826 & 100 & $\leq 0,12-0,5$ & $\leq 12-0,25$ \\
& Ramoplanin & 100 & $1-2$ & $0,5-2$ \\
& Teicoplanin & 100 & $1-2$ & $1-4$ \\
Macrolide/Lincosamine/ & Vancomicyn & 100 & $1-2$ & 1 \\
Streptogramim & Clarithromycin & 8 & $\geq 32$ & $0,25-\geq 32$ \\
& Clindamycin & 8 & $\geq 32$ & $\leq 0,12-\geq 32$ \\
& Erytromycin & 25 & $\geq 16$ & 0,25 \\
& Daptomycin & 100 & $\geq 16$ & $0,25-\geq 16$ \\
& Roxithromycin & 8 & $2-4$ & 2 \\
RP 59.500 & 100 & $\geq 32$ & $0,5-\geq 32$ \\
Aminoglycosides & Gentamicin & 17 & $0,5-1$ & $0,25-0,5$ \\
& Amicacin & 33 & $16-\geq 32$ & $0,5-\geq 32$ \\
& Tobramicyn & 17 & $8-\geq 64$ & $1-4$ \\
Others & Cloranphefenicol & 33 & 832 & $0,25-\geq 32$ \\
& Tetracyclin & 25 & $0,5-\geq 32$ & $4-\geq 64$ \\
& Rifampicin & 75 & $1-\geq 8$ & $0,5-\geq 32$ \\
& Mupirocin & 100 & $\leq 5$ & $\leq 12-\geq 8$ \\
\hline
\end{tabular}




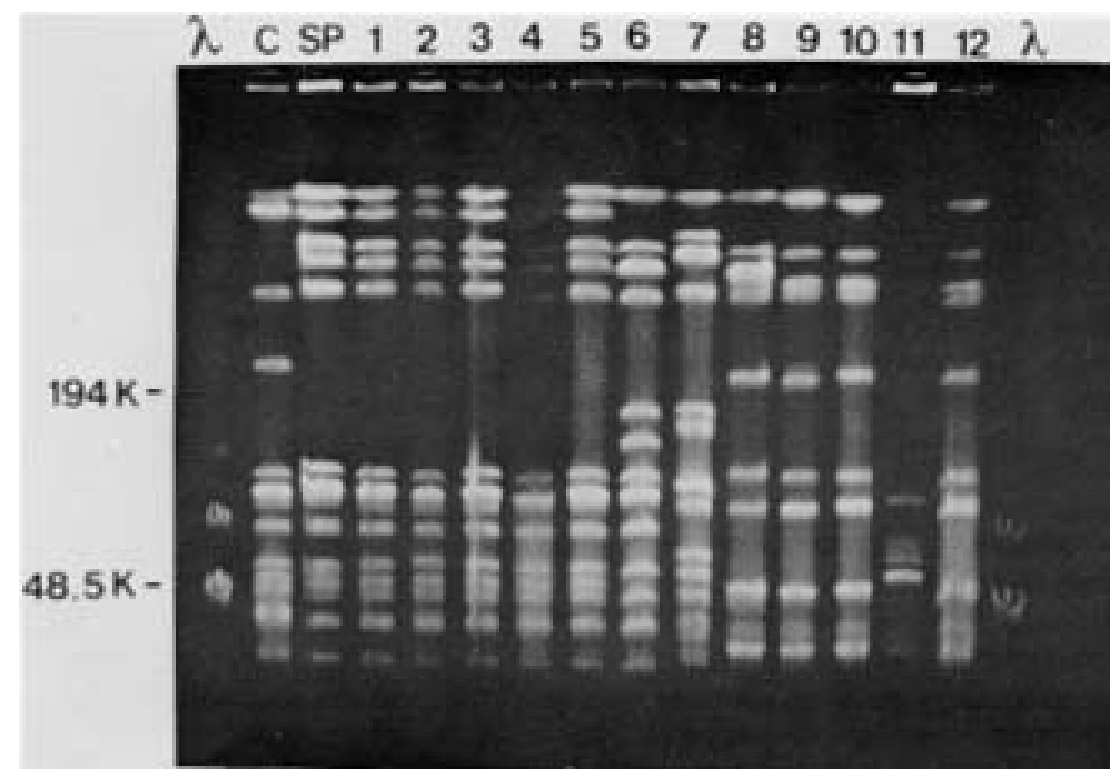

Pulsed-field gel electroresis pattern of chrDNA from Staphylococcus aureus isolates after d digestion with Sma I and eletrophoresis using switch time ramping from 5 to 30s. C: control; SP: MRSA from Oswaldo Cruz Hospital (São Paulo) showing the SP pattern; 01 to 12: strains isolated from the University Hospital, João Pessoa, Paraíba. Molecular size markers $\lambda$ DNA ladders $(48,5) K b)$.

\section{DISCUSSION}

The infections caused by $S$. aureus methicillinresistant strains represent an important and increasing problem. In recent years, there has been a trend toward supplementing the more traditional epidemiological methods with a variety of molecular approaches aimed at more directly assessing the genetic relatedness of strains. Because the diversity and stability of the DNA profiles, PFGE have been very accurate for epidemiological typing of MRSA isolates (Struellens et al. 1992).

The generally used phagetyping is often unsatisfactory in differentiating S. aureus strains, since its typeability is lower than other typing methods. In this study $50 \%$ of the isolates, considered for molecular analysis, were non typeable by this method, whereas all of them were typeable by PFGE. All the strains MRSA were characterized by the Crystal system that provides a rapid (4 $\mathrm{hr}$ ) identification, and allows apropriate antibiotic theraphy to be implemented sooner than standard methods.

Epidemiologic typing of MRSA strains has proven to be particularly difficult because most strains are derived from relatively few clones (Carles-Nurit et al. 1992, Schlichting et al. 1993). Our results agreed with other studies (Branchini et al. 1993, Sader et al. 1994) that demonstrated the similarity between strains isolated from different hospitals. A few different clones of MRSA are present in our enviroment and the SP pattern belongs to a common MRSA clone that is widely present in the hospitals of São Paulo (Sader et al. 1994). The genetic relatedness of MRSA isolates reported in several countries support this hipothesis (Struellens et al. 1992). In conclusion, the results of the present study suggest the dissemination of a MRSA clone in João Pessoa which is similar to that described in other cities in Brazil.

\section{REFERENCES}

Blair J, Williams REO 1961. Phage typing of staphylococci. Bull WHO 24: 771-784.

Brown DFJ, Brown L 1991. Evaluation of the E test: a novel method of quantifying antimicrobial activity. J Antimicrob Chemother 27: 185-190.

Boyce JM, Jackson MM, Pugliese G, Batt MD, Fleming D, Gerner J, Hartstein AI, Kaufmann CA, Simmons M, Wenstein R, Williams CO 1994. Methicillinresistant Staphylococcus aureus (MRSA): a brief for acute care hospitals and nursing facilities. Infect Control Hosp Epidemiol 15: 105-115.

Branchini MLM, Moethland VH, Tresoldi AT, Nowakonsky AV, Dias MB, Pfaller MA 1993. Application of genomic DNA subtyping by pulsedfield gel electophoresis and restriction enzyme analysis of plasmid DNA to characterize methicillinresistant Staphylococcus aureus from two nosocomial outbreaks. Diagn Microbiol Infect Dis 17: 275-281.

Carles-Nurit MJ, Christophle B, Broche S, Gouby A, Bouziges N, Ramuz H 1992. DNA polimorphisms in methicillin-sensitive and methicillin-resistant strains of Staphylococcus aureus. J Clin Microbiol 30: 2092-2096. 
De Lencastre HSA, Figueredo AS, Urban C, Rahal J, Tomasz A 1991. Multiple mechanisms of methicillin-resistant and improved methods for detection in clinical isolates of Staphylococcus aureus. Antimicrob Agents Chemother 35: 632-639.

Hackbarth CJ, Chambers HF 1989. Methicillin-resistant staphylococci. Detection methods and treatment of infections. Antimicrob Agents Chemother 33: 995999.

Halley RW, Hightower AW, Khabbaz RF, Thornsberry C, Martone WJ, Allen JR, Hughes J M 1982. The emergence of methicillin-resistant Staphylococcus aureus in the United States hospitals. Ann Intern Med 97: 297-308.

Hartman BJ, Tomasz A 1984. Low affinity penicillinbinding protein associated with beta-lactam resistance in Staphylococcus aureus. J Bacteriol 158: 513-516.

Kloos WE, Lambe DW 1991. Staphylococcus. p. 222237. In: A Ballows, WD Hausler Jr, KL Hermann, HD Isenberg, HJ Shadomy. (eds.) Manual of Clinical Microbiology. 5th ed. American Society for Microbiology, Washington DC.

Knapp CC, Ludwig MD, Washington JA 1994. Evaluation of BBL crystal MRSA ID system. J Clin Microbiol 32: 2588-2589.

National Committee For Clinical Laboratory Standards. 1993. Performance standards for antimicrobial susceptibility tests for bacterial that grow aerobically. Approved standard M7-T2. 2nd ed NCCLS. Villanova Pa.

Pfaller MA, Hollis RJ, Sader, HS 1994. Cromossomal restriction fragment analysis by pulsed-field electrophoresis. In H D Isenberg. Clinical Microbiology Handbook. Suppl. I. American Society for Microbiology, Washington DC.
Prevost G, Jaulac B, Piemont Y 1992. DNA fingerprinting by pulsed-field gel electrophoresis is more effective than ribotyping in distinguishing among methicillin- resistant Staphylococcus aureus isolates. J Clin Microbiol 30: 967-973.

Qadri SMH, Ueno Y, Imambaccus H, Almodovar E 1994. Rapid detection of methicillin-resistant Staphylococcus aureus by crystal MRSA ID system. J Clin Microbiol 32: 1830-1832.

Richard P, Meyran M, Carpenter E, Drugeon H 1994. Comparison of phenotipic methods and DNA hibridization for detection of methicillin-resistant Staphylococcus aureus. J Clin Microbiol 32: 613617.

Sader HS, Pignatari AC, Hollis R, Jones RN 1994. Evaluation of interhospitalar spread of methicillinresistant Staphylococcus aureus in São Paulo, Brazil, using pulsed-field gel electrophoresis of cromossomal DNA. Inf Control Hosp Epidemiol 15: 320-323.

Schlichting C, Branger C, Fournier JM, Witte W, Boutonnier A, Woltz C, Goullet P, Doring G 1993. Typing of Staphylococcus aureusby pulsed-field gel electrophoresis, zymotyping, capsular typing and phage typing: resolution of clonal relationships. J Clin Microbiol 31: 227-232.

Struellens MJ, Delplano A, Godard C, Maes N, Serrus E 1992. Epidemiologic typing and delineation genetic relatdness of methicillin-resistant Staphylococcus aureus by macrorestriction analysis of genomic DNA by using pulsed-field gel electrophoresis. J Clin Microbiol 30: 2599-2605.

Thornsberry C, Mc Dougal LK 1983. Sucessful use of broth microdilution in susceptibility tests for methicillin-resistant (heteroresistant) staphylococci. J Clin Microbiol 18: 1684-1691. 
Clonal Diversity of $S$. aureus $\bullet$ L Santos Fo et al. 